\title{
Hypercapnia as the influencing factor of pulse oximetry
}

\section{To the Editors:}

We would like to comment on the recently published study by MuÑoz et al. [1], which analysed accuracy and precision of pulse oximetry at different carbon dioxide arterial tension $\left(\mathrm{Pa}, \mathrm{CO}_{2}\right)$ levels. Although the paper investigates an interesting hypothesis, significant limitations should be addressed.

The most important limitation is that the reported mean $\mathrm{Pa}, \mathrm{CO}_{2}$ of $45.3 \pm 8.0 \mathrm{mmHg}$ does not exactly reflect hypercapnia. As $45.0 \mathrm{mmHg}$ is an accepted boundary value for $\mathrm{Pa}, \mathrm{CO}_{2}$, the conclusions drawn by MuÑz et al. [1] are not adequately supported by their results. While the authors excluded blue nail polish, other colours, such as dark green or black, may have even more pronounced effects $[2,3]$.

One significant statement MuÑz et al. [1] make is that $\mathrm{Pa}, \mathrm{CO}_{2}$ might directly affect pulse oximetry readings. They emphasise that carbohaemoglobin may be the cause of this measurement bias. The sole effect of carbohaemoglobin was neither analysed nor measured in the study by MuÑz et al. [1], nor is their hypothesis supported by any other published study. However, hypercapnia has been proven to have an indirect effect due to vasoconstriction and consecutive alterations of perfusion [4], giving a more likely explanation for the effects observed.

The calculation of bias by MuÑoz et al. [1] was not performed as usual or as suggested by BLAND and ALTMAN [5]: the gold standard should be subtracted from the measured value e.g. bias equalled arterial $\mathrm{O}_{2}$ measured by pulse oximetry $\left(\mathrm{Sp}, \mathrm{O}_{2}\right)$, minus arterial $\mathrm{O}_{2}$ saturation $\left(\mathrm{Sa}_{2} \mathrm{O}_{2}\right)$. For data interpretation, the use of a regression line for the cloud of data points does not seem adequate. Removal of one single data point $(\sim 64 \mathrm{mmHg}$ on the $\mathrm{x}$-axis; $-13 \%$ on the $y$-axis; see figs $1 \mathrm{a}$ or $2 \mathrm{c}$ of [1]), might lead to a horizontal regression line similar to the lines in the other figures.

Although pulse oximetry is an established technique used regularly in the clinical setting, newer and improved devices require continued re-evaluation of limitations and influencing factors. We wholeheartedly agree with MUÑOz et al. [1] that arterial blood gas analysis remains the gold standard, supported but not replaced by pulse oximetry readings.

\section{J. Hinkelbein and H.V. Genzwuerker}

Dept of Anaesthesiology and Intensive Care Medicine, University Hospital Mannheim, Mannheim Medical Faculty of the University of Heidelberg, Mannheim, Germany.

\section{STATEMENT OF INTEREST}

None declared.

\section{REFERENCES}

1 Muñoz X, Torres F, Sampol G, Rios J, Martí S, Escrich E Accuracy, reliability of pulse oximetry at different arterial carbon dioxide pressure levels, Eur Respir J 2008; 32: 1053-1059.
2 Coté CJ, Goldstein EA, Fuchsman WH, Hoaglin DC The effect of nail polish on pulse oximetry, Anesth Analg 1988; 67: 683-686.

3 Hinkelbein J, Genzwuerker HV, Sogl R, Fiedler F Effect of nail polish on oxygen saturation determined by pulse oximetry in critically ill patients, Resuscitation 2007; 72: 82-91.

4 Jensen LA, Onyskiw JE, Prasad NG Meta-analysis of arterial oxygen saturation monitoring by pulse oximetry in adults, Heart Lung 1998; 27: 387-408.

5 Bland JM, Altman DG Statistical methods for assessing agreement between two methods of clinical measurement, Lancet 1986; 1: 307-310.

DOI: $10.1183 / 09031936.00114608$

From the authors:

We appreciate your interest in our paper [1] and are grateful for the opportunity to clarify some issues.

We agree that several types of nail polish can affect pulse oximeter readings. Actually, none of the patients in our study were wearing any nail polish during pulse oximetry; hence, we believe that the results obtained are reliable.

As for the question of hypercapnia, most authors establish hypercapnic status on the basis of carbon dioxide arterial tension $\left(\mathrm{Pa}_{1} \mathrm{CO}_{2}\right)$ levels $>45 \mathrm{mmHg}(>5.99 \mathrm{kPa})$. J. Hinkebein and H.V. Genzwerker consider that a mean of $45.3 \pm 8.0 \mathrm{mmHg}(6.04 \pm 1.07 \mathrm{kPa})$ does not exactly reflect hypercapnia. In this respect, it is important to remember that the mean is a descriptive value that addresses only the central trend, not the variability. As we show in table 2 [1], at least one-third of our patients (upper tertile in table 2; $n=274$ ) had $P \mathrm{a}, \mathrm{CO}_{2}$ values $>48 \mathrm{mmHg}(>5.99 \mathrm{kPa})$. In fact, we believe that the wide spectrum of $\mathrm{Pa}_{1} \mathrm{CO}_{2}$ values included is one of the strong points of the study.

With regard to the comments on our use of Bland and Altman analysis, we consider that this is not an issue since the difference between two values is completely symmetrical and the interpretation of the results is not altered. It is also important to note that the mean bias as described by Bland and Altman assumes that there is no trend along the mean of the two measurement axis. We included the complementary regression analysis with the sole purpose of addressing this issue.

The mechanism by which $\mathrm{Pa}, \mathrm{CO}_{2}$ variation can affect agreement between arterial oxygen saturation $\left(\mathrm{Sa}_{2} \mathrm{O}_{2}\right)$ and arterial oxygen saturation measured by pulse oximery $\left(S_{\mathrm{p}}, \mathrm{O}_{2}\right)$ is unknown. J. Hinkebein and H.V. Genzwerker suggest the possibility that hypercapnia-induced vasoconstriction might be responsible for the discordance between these determinations. However, the effect that hypercapnia plus hypoxaemia (the situation of most of the patients in our study) might have on vascular tone is uncertain. Although this hypothesis cannot be excluded, the fact that a decrease in $\mathrm{Pa}_{1} \mathrm{CO}_{2}$ also alters agreement between $\mathrm{Sa}_{1} \mathrm{O}_{2}$ and $\mathrm{Sp}, \mathrm{O}_{2}$ undermines this interpretation. It could, 